\title{
Por uma epistemologia da gambiarra: invenção, complexidade e paradoxo nos objetos técnicos digitais ${ }^{a}$
}

\author{
Towards a gambiarra epistemology: invention, \\ complexity and paradox in digital technical objects
}

\author{
J OSÉ MESSIA S \\ Universidade Federal do Maranhão, Programa de Pós-Graduação em Comunicação. Imperatriz - \\ MA, Brasil \\ IVAN MUS S A \\ Universidade Federal do Rio Grande do Norte, Departamento de Comunicação Social. Natal - \\ RN, Brasil
}

\section{RESUMO}

Associando processos de constituição de objetos técnicos digitais ao conceito de gambiarra, busca-se revelar os modos de existência que tornam a gambiarra um operador fundamental às relações entre técnica, corpo e sociedade. As dimensões estéticas, políticas e cognitivas do conceito compõem uma vertente alternativa da tecnicidade que permite elucidar o caráter complexo e muitas vezes paradoxal das formações sociotécnicas digitais. A demonstração empírica dessas ideias se dará em três níveis: o redirecionamento das capacidades de processamento de consoles de video games e placas de vídeo; as reconfigurações do software e das interfaces gráficas; e a consequente invenção de ritmos e formas de ver, sentir e agir nos video games.

Palavras-chave: Gambiarra, objetos técnicos digitais, games, complexidade

\section{ABSTRACT}

By associating processes of constitution of digital objects to the concept of gambiarra, we aim to uncover the modes of existence that render the gambiarra as a crucial operator in the relationship between techniques, bodies and society. The aesthetic, political, and cognitive dimensions of the concept form an alternative version of technicity that allows us to understand the complex and even paradoxical aspects of digital sociotechnical formations. The empirical demonstration of these ideas will take place in three levels: the redirection of capacities of processing in video game consoles and video cards; the reconfiguration of software and user interfaces; and the resulting invention of rhythms and ways of seeing, feeling and acting in video games.

${ }^{a}$ O presente trabalho foi realizado com apoio da Coordenação de Aperfeiçoamento de Pessoal de Nível Superior - Brasil (CAPES) - Código de Financiamento 001 .

${ }^{\mathrm{b}}$ Professor adjunto do curso de Comunicação Social/ Jornalismo e do Programa de Pós-Graduação em Comunicação da Universidade Federal do Maranhão, campus Imperatriz. Foi bolsista de Pósdoutorado (Capes/PNPD) no PPGCOM/UFF. Coordenador do grupo de pesquisa GamerLab/UFMA. Orcid: http://orcid.org/0000-00016950-220X. E-mail: jose.cmsf@ufma.br

${ }^{c}$ Professor substituto do Departamento de Comunicação da Universidade Federal do Rio Grande do Norte (Decom/UFRN) e vicecoordenador do GP Games da Intercom. Orcid: https://orcid. org/0000-0003-1831-2822.

E-mail: ivanmussa@gmail.com

Keywords: Gambiarra, digital technical objects, games, complexity 
${ }^{1}$ No original: "Modernity ends with the rise of a technological consciousness, meaning both the consciousness of the power of technology and the consciousness of the technological condition of the human". Esta e demais traduções, dos autores.

${ }^{2} \mathrm{O}$ sentido costumeiro da palavra gambiarra faz referência a construções improvisadas, desviantes - por exemplo, um desvio de fiação para roubar energia elétrica - e tem sua etimologia enraizada na palavra gamba, que significa "perna", em italiano (Bruno, 2017, p. 137).
Do ponto de vista da Teoria dos Sistemas Complexos, a vida é uma matéria organizada que, aprendendo a modificar sua própria estrutura para responder a alterações do meio, passou a conectar as durações bilionesimais das reações moleculares aos milhares de anos das transformações ambientais, aos milhões de anos das transformações geológicas, às centenas de milhões das transformações astrofísicas. A aceleração técnica vigente na contemporaneidade superpôs a essa conexão entre os ritmos materiais e biológicos o prestíssimo das produções culturais. Luiz Alberto Oliveira (2003, p. 167)

A modernidade termina com a ascensão de uma consciência tecnológica, significando a consciência do poder da tecnologia e a consciência da condição tecnológica do ser humano ${ }^{1}$. Yuk Hui (2016b, p. 42)

\section{INTRODUÇÃO}

O LONGO DA história das tecnologias digitais, é possível identificar
uma miríade de fenômenos que indicam uma constatação parado-
xal: as indústrias bilionárias com seus circuitos produtivos racionais e rígidos muitas vezes impõem mais empecilhos à inovação do que ambientes desprovidos de recursos e investimento. Poderíamos alegar que é a ausência de esquemas de coerção e cobrança de resultados que permite o florescimento da criatividade livre. Este artigo, porém, busca uma abordagem inversa: em vez de apontar a falta de constrangimentos como motor da inovação, pretendemos investigar a natureza das interações que possibilitam outros modos de produção. Se existem aqueles calcados na abundância de recursos e nas lógicas racionais estabelecidas, veremos por outro lado processos de concepção e construção que nascem de movimentos aberrantes e lógicas irracionais fundamentados na precariedade, no improviso e no desvio de funções. É o que chamaremos, aqui, de gambiarra ${ }^{2}$.

É necessário, antes de prosseguir, apontar a diferença entre a definição convencional de gambiarra (Rosas, 2007) e a conceituação que pretendemos desenvolver nesse texto. O objetivo é estender a análise para além de objetos e construções marcados pelo contexto socioeconômico de pobreza, sobretudo o brasileiro. A hipótese é que os parâmetros de precariedade e improviso característicos desse enquadramento podem ser tomados como vetores conceituais capazes de potencializar nossa capacidade de entendimento dos fenômenos técnicos e suas repercussões políticas e estéticas. 
Este problema de estudo deve ser abordado sobre uma base tripla, orientada primeiro por uma concepção cognitiva (Kastrup, 2007; Varela, Thompson, \& Rosch, 2001) do fenômeno da gambiarra combinada com um aprofundamento de seu viés político e estético (Souriau, 2015); em segundo, pelo referencial da filosofia da técnica (Hui, 2016a; Simondon, 2017) informado pela epistemologia da complexidade (Delanda, 2002/2005; Oliveira, 2003); e finalmente, por uma discussão das dimensões afetivas e políticas da gambiarra, bem como de seus atributos paradoxais e dissonantes (Lapoujade, 2016; Massumi, 2002).

Ao abarcar uma dimensão política, a noção de gambiarra busca expressar uma cosmologia que mobiliza os vetores da complexidade, do paradoxo e da alteridade para uma investigação da dimensão técnica do conhecimento. Essa cosmologia se alimenta da ideia de invenção (Kastrup, 2007) e do perspectivismo ameríndio de Viveiros de Castro (2013), assim como de outros autores da chamada virada ontológica $^{3}$. A ideia de gambiarra, portanto, traduz um processo de concretização (Simondon, 2017), cujas características elucidam os modos de existência de objetos técnicos, sob o filtro da epistemologia da complexidade e suas derivações dissonantes, ligações afetivas e aspectos possivelmente paradoxais. Por isso, a demonstração empírica presente no artigo privilegia um olhar sobre a técnica que desloca o humano e uma noção essencialmente antropocêntrica de política do cerne da discussão. Neste contexto, a dinâmica que configura a gambiarra como um processo complexo e dissonante de concretização é a sua ancoragem na chave precariedade-improviso, da qual trataremos adiante. A partir do pensamento de Gilbert Simondon (2017) sobre os modos de existência, o presente texto propõe uma conceituação de gambiarra que busca repensar o estatuto do objeto técnico digital dentro das teorias da comunicação. A gambiarra, assim, tem o potencial de expressar as derivações e contingências tanto das tecnologias sofisticadas quanto das mais precárias; ou, mais precisamente, mostrar o quão precárias e contingenciais são as conexões ou vínculos (Sodré, 2014) que agregam essas tecnologias. Nas tecnologias digitais, essas conexões aparecem nas potencialidades de manipulação de hardware, do processamento gráfico e na forma que assumem na interação humano-computador.

Sobre essa plataforma teórica, será projetado um arcabouço empírico que busca evidenciar as dinâmicas de contingência, limitações, improvisações e mediações encontradas em três escalas de análise na cultura digital. Em primeiro lugar, a manipulação de hardware que redireciona sua função e reconfigura suas capacidades de ação - nessa categoria, trataremos do uso de consoles de video games ligados em rede para a montagem de supercomputadores e também do uso de placas de vídeo vendidas para rodarem jogos eletrônicos que são reutilizadas para mineração de criptomoedas. Na camada do software e da interface gráfica,
${ }^{3}$ Representada principalmente por autores como Eduardo Viveiros de Castro, Phillipe Descola, Tim Ingold e Bruno Latour, a chamada virada ontológica (ontological turn) na Antropologia trata justamente de um grupo de conceitos e temáticas que deslocam a centralidade do humano enquanto sujeito do processo de conhecimento, tanto na área do saber em que se origina, como numa perspectiva mais geral. 
trataremos do improviso e da precariedade que impulsionaram a invenção do mouse e do contexto de restrição e limitações que cercou o advento do espaço tridimensional nos video games e, por fim, trataremos efetivamente da conexão humano-máquina, ou seja, da cognição do jogador que depara com os esquemas e lógicas irracionais movimentadas pelos ritmos sensoriais dos video games.

Tudo isso está ancorado em pesquisas já desenvolvidas no contexto brasileiro, a exemplo do trabalho de Bruno (2017). A partir dessas e de outras iniciativas que serão elencadas à medida que forem relevantes para o texto, procuramos não apenas listar visões epistemológicas e ilustrá-las com exemplos no mundo dos jogos. Mais do que isso, nossa proposta é contribuir e avançar com o estudo da gambiarra enquanto perspectiva epistemológica, demonstrando a viabilidade dessa forma de conhecer no contexto dos video games - além de expor os mecanismos a partir dos quais nossas conclusões puderam ser obtidas e defendidas.

Ao demonstrar que esses processos de alta complexidade também incorporam o modo de existência da gambiarra, procura-se sair de um contexto pós-colonial de precariedade como desigualdade socioeconômica regional, para uma ideia de precariedade e improviso como forma de conhecer. Não o que se pode conhecer (ontologia), mas como se pode conhecer a partir da comunicação/mediação entre ordens de magnitude (Simondon, 2017). Neste contexto, a gambiarra atravessaria essas ordens como uma forma de conhecimento técnico, seja no âmbito socioeconômico, estético, cognitivo ou político. Faríamos a passagem de um contexto pós-colonial (de escassez socioeconômica, desigualdade e exploração) para uma epistemologia pós-colonial, contribuindo para a invenção de uma cognição canibal e perspectivista. "Absorver o outro e, neste processo, alterar-se", como afirma Viveiros de Castro (2013, p. 207).

\section{A DIMENSÃO ESTÉTICA DA COMPLEXIDADE}

Gilbert Simondon (2017) acredita que, após a revolução industrial, o homem deslocou-se do centro (o artesão circundado por ferramentas) para a periferia da lógica produtiva (as máquinas circundadas por operários). Contudo, a partir da cognição corporificada e de certa perspectiva antropofágica, tem-se que essa suposta alienação do papel da técnica no cotidiano não se dá em todas as ordens de magnitude (Simondon, 2017) ou níveis de mediação (Grusin, 2015). Numa noção complexa de conhecimento, a gambiarra representa uma conexão entre homem e técnica em que o próprio corpo é atravessado no nível dos afetos (Massumi, 2002), da biologia (Varela et al., 2001) e, claro, da cultura - sem que a percepção consciente precise ser acionada. 
Andy Clark (2001) utiliza a anedota do bartender que usa a sequência de copos e seus formatos para lembrar os drinks que precisa preparar, já Donald Norman (1993) lembra do recurso da repetição e compartilhamento de informações entre tripulantes de um navio ou avião como forma eficiente de tocar o barco. Esses exemplos remetem ao processo que Lakoff e Johnson (1999) chamaram de cognição não consciente (cognitive unconscious ${ }^{4}$ ), no qual "a mente não é apenas corporificada, mas corporificada de tal forma que nossos sistemas conceituais se baseiam amplamente nas semelhanças com nossos corpos e os ambientes em que vivemos"s (p. 6).

Em suma, os seres humanos não precisam ser necessariamente comandantes centrais, mesmo em processos em que são aparentemente parte integrante e essencial, como pilotar um navio ou avião. Como no exemplo do formigueiro, comportamentos inteligentes podem emergir do que aparentemente é puro caos (Oliveira, 2003). As formas complexas de organização deslocam a centralidade da consciência, pulverizando a racionalidade e erguendo uma lógica em que a ação - ou agência - é compartilhada entre os atores humanos e não humanos, mesmo no processo "evolutivo" de design de objetos aparentemente planejados de forma antropocêntrica, como relata Norman (1993):

Muitas das propriedades essenciais de uma ação compartilhada efetiva parecem resultar de efeitos colaterais "acidentais" do jeito antiquado de fazer as coisas.... Suspeito que o procedimento não é tão acidental quanto possa parecer, mesmo que não tenha sido conscientemente produzido .... Esse é um processo de evolução natural, e pode levar a resultados notavelmente eficientes, mesmo que ninguém esteja no comando, mesmo que ninguém esteja ao menos ciente do processo $^{6}$. (pp. 144-145)

Explicita-se, assim, uma epistemologia corporificada, que depende menos de uma faculdade ou capacidade intencional humana, e mais de um processo de derivações codeterminadas, no qual a invenção, no sentido dado por Virginia Kastrup, mobiliza os indivíduos ao invés de ser mobilizada por eles. Nesse contexto, a especificidade da gambiarra, quando comparada a outros conceitos empregados na análise da cultura digital, está no seu engajamento com as ideias de precariedade, improviso e alteridade. Melhor: traduz um encontro com a alteridade, condicionado pelas categorias de precariedade e improviso tomadas sob um ponto de vista complexo que inclui as agências não humanas de políticas públicas, infraestrutura técnico-científica, contextos socio-históricos, capacitação e letramentos cognitivos, entre outros efeitos e demandas do capitalismo na Modernidade.
${ }^{4}$ Não confundir com o inconsciente freudiano.

${ }^{5}$ No original: “The mind is not merely embodied, but embodied in such a way that our conceptual systems draw largely upon the commonalities of our bodies and of the environments we live in".

${ }^{6}$ No original: "Many of the essential properties of effective shared action seem to result from 'accidental' side effects of the oldfashioned way of doing things. ... I suspect the procedure is not quite as accidental as it might seem, even if it was never consciously designed. ... This is a process of natural evolution, and it can lead to remarkably efficient results, even if nobody is in charge, even if nobody is aware of the process". 
Walter Mignolo, em The darker side of Western Modernity (2011), realiza uma detalhada explanação sobre as diferentes formas de criticar e apresentar alternativas aos efeitos da Modernidade. Essas escolas, como os Estudos Subalternos, na Ásia, que fundam boa parte do que se entende como estudos pós-coloniais; $\mathrm{e}, \mathrm{em}$ contraponto, a decolonização, proveniente de Aníbal Quijano e a decolonialidade, do próprio Mignolo (esses últimos mais próximos) se tornaram referências para alguns dos principais conceitos dentro da luta anti-hegemônica. No entanto, para o autor, está claro que cada uma possui um determinado escopo, uso e referencial teórico, não devendo ser casualmente agrupadas e nem utilizadas de forma intercambiável. Para fins deste trabalho, os pontos de vista de Mignolo e os pós-coloniais são relevantes, por isso o uso dos dois termos.

${ }^{8} \mathrm{Na}$ chamada trilogia Império (Hardt \& Negri, 2001, 2005, 2016), os autores chamam de inclusão diferencial na informatização da produção o processo pelo qual os pobres, subempregados e migrantes são incluídos na produtividade do capital (e na instrumentalização técnica/ digital que ela produz).

${ }^{9}$ No original: "a radical alterity will have to be asserted in order to leave room for heterogeneity, and thereby to develop different epistemes based on traditional metaphysical categories, a task which opens the way to the veritable question of locality".

${ }^{10} \mathrm{No}$ original: "the orders of magnitude may give us different bodies of knowledge that appear to be exclusive to one another".
Encontramos aí seu viés político, investido em uma cosmologia decolonial ${ }^{7}$ (Mignolo, 2011) e representado por uma perspectiva "regional", um ponto de vista da regionalidade, mas que - paradoxalmente - não se restringe a uma localização geográfica. Essa abordagem se inspira no que Hardt e Negri (2005) propuseram com a ideia de multidão e sua condição comum de pobreza ${ }^{8}$, ou Achille Mbembe (2017) com um devir negro do mundo, em que a condição de subjugação do negro é a constante que definiu a modernidade e a própria noção de humanidade. Longe de serem generalizações abstratas, a semelhança entre essas propostas e a gambiarra se situa na forma como elas produzem mundos e, portanto, cosmologias próprias.

Em Hardt e Negri $(2001,2005,2016)$, a relação entre pobreza e multidão trata justamente de ordens de magnitude, e não categorias ontológicas de prescrição, em uma crítica ao rígido conceito de classe do marxismo tradicional. Já em Mbembe (2017), o devir negro do mundo expõe uma propriedade da era moderna subjacente às relações cotidianas. Com a introdução da dimensão técnica, queremos expor as forças divergentes que atravessam as formas de produzir conhecimento; é o fato de essas forças divergentes existirem que estabelece algo em comum entre elas. Assim, como argumenta Yuk Hui (2016b) ao propor sua filosofia chinesa da técnica, "uma alteridade radical vai precisar ser afirmada para deixar espaço para a heterogeneidade, e assim desenvolver diferentes epistemes baseadas em categorias metafísicas tradicionais, uma tarefa que abre caminho para verdadeira questão da localidade" ${ }^{\prime 9}$ (p. 30). Ou seja, uma investigação "regional" sobre a técnica precisa levar em consideração as restrições e imposições globais provenientes de uma herança hegemônica moderna. É neste espaço limítrofe que está localizada a gambiarra.

É possível explicitar a precariedade e o improviso e, portanto, a gambiarra, como fatores determinantes para o entendimento da constituição sociotécnica da cultura digital. A partir de uma breve reflexão (desdobrada na quarta parte deste artigo) sobre as condições de usabilidade dos objetos técnicos digitais, busca-se demonstrar como a precariedade e o improviso da gambiarra capitaneiam processos complexos, dissonantes e paradoxais de individuação, pois “as ordens de magnitude podem nos dar diferentes corpos de conhecimento que parecem ser excludentes um ao outro"10 (Hui, 2016a, pp. 29-30).

Na gambiarra, vê-se o encontro potencialmente excludente entre subjetividade e técnica, cuja fricção não seria um empecilho, mas sim um fator vital para compreender o atual estado da cultura digital e dos níveis de descrição que fundamentam a interação humano-máquina na sociedade da informação. Alexander Galloway (2012) tratou do caráter arbitrário do processamento gráfico digital, uma vez que o poder bruto de processamento de dados pode levar 
a múltiplas direções em termos de interação humano-computador. Explorando essa premissa, uma abordagem sobre a manipulação destes processadores e do resultado gráfico de seu potencial técnico demonstrará a presença da gambiarra, mesmo em tecnologias sofisticadas de computação.

A esse pareamento político-técnico, podemos acrescentar a dimensão dos afetos e da estética. Em The different modes of existence, Etiene Souriau (2015) constrói conceitos que podem ser operados em conjunção com a gambiarra, designando-a como um processo de invenção cognitiva e individuação técnica que se alimenta dessas múltiplas formas da precariedade. Souriau pensa epistemologia e estética como facetas de um mesmo movimento, como afirmam Isabelle Stengers e Bruno Latour (2015):

Ele tinha uma grande ambição, um projeto monumental, em mente para seu campo .... A Estética deveria se tornar um tipo de disciplina científica direcionada à multiplicidade de seres que constituem as obras, seres que agora são entendidos em termos das formas que eles concebem. Essas obras, portanto, constituem o que Souriau chama de pleroma, um mundo de seres instaurado em "patuidade": cada um em sua radiância total, sua própria presença singular e fundamental ${ }^{11}$. (p. 24)

Essa junção de estética e epistemologia é análoga ao que pretendemos com o entendimento das várias camadas da cultura digital. Encontrar as gambiarras que residem nos gestos e apreensões estéticas, nos modos de ser, pensar e interagir e nos arranjos sociotécnicos formadas a partir de seus agenciamentos heterogêneos (inusitados ou até improváveis). A chave metodológica para essa empreitada está em uma especulação que vise a atribuição de intencionalidade/ agência, como nas práticas xamânicas do perspectivismo ameríndio (Viveiros de Castro, 2013), mas que também contemple a instauração de existências sem substância e por fazer, como aponta Peter Pál Pelbart (2017) a partir de Souriau e de sua ideia de incompletude.

Para tal, um ponto de vista ancorado na complexidade permite identificar essas agências não humanas e instâncias de mediação inventiva (Kastrup, 2007; Messias, 2020) de forma a buscar, propor e eventualmente vivenciar cosmologias que confrontem as leituras hegemônicas da Modernidade. Formando, assim, um duplo movimento: o desvelamento dessas imbricações e a proposição de alternativas a esses programas e normatizações.

De forma a cumprir o intento paradoxal de acessar os modos de existência que o próprio humanismo refuta - ou que pelo menos estão além de sua compreensão -, a especulação nos ajuda a conhecer, mesmo que parcialmente, processos como o da cognição não consciente (Lakoff \& Johnson, 1999), a
${ }^{11}$ No original: "He [Souriau] had a grand ambition, a monumental project, in mind for his field, one that began to take shape after 1925. Aesthetics must become a type of scientific discipline directed toward the multitude of beings that constitute works, beings that are now understood in terms of the forms they realize. These works therefore constitute what Souriau calls a pleroma, a world of beings instaured in 'patuity': each one in its total radiance, its own singular and fundamental presence". 
${ }^{12}$ No original: "if it is true that, in order to apprehend the universe in all its complexity, it is necessary to equip thought not only for all the multicolored rays of existence, but even for a new light, for a white light, unifying those rays in the luminosity of a surexistence which surpasses all those modes without subverting their reality".

${ }^{13}$ No original: "Although the realm of intensity that Deleuze's philosophy strives to conceptualize is transcendental in the sense that it is not directly accessible to experience, it is not transcendent, it is not exactly outside experience either. It is immanent to it-always in it but not of it. Intensity is immanent

to matter and to events, to mind and to body and to every level of bifurcation composing them and which they compose". nanosfera da mecânica quântica, os labirintos do psiquismo e dos afetos, da produção de subjetividade, e claro, da fruição estética. A especulação de agência satisfaz aquilo que Souriau (2015) chamou de luz branca numa metáfora apta às referências da física quântica e da relatividade. Segundo ele:

Se é verdade que, para apreender o universo em toda sua complexidade, é necessário instrumentalizar o pensamento não apenas para todo os raios multicoloridos da existência, mas mesmo para uma nova luz, uma luz branca, unificando todos esses raios na luminosidade de uma superexistência [surexistence] que ultrapassa todos aqueles modos sem subverter suas realidades ${ }^{12}$. (p. 101)

Acionando um dos principais adágios atribuídos à complexidade: o todo é maior do que a soma de suas partes (Oliveira, 2003), a superexistência de que trata Souriau (2015) aparece exemplarmente na discussão sobre afeto na filosofia pós-estruturalista. Brian Massumi (2002) traduz essa questão como um problema entre imanência e transcendência, tal qual se apresenta na obra de Deleuze:

Embora o domínio da intensidade que a filosofia de Deleuze se esforça para conceituar seja transcendental no sentido de que não é diretamente acessível à experiência, também não é transcendente, não estando exatamente fora da experiência. É imanente a ela - sempre nela, mas não dela. Intensidade é imanente à matéria e aos eventos, à mente e ao corpo e a todo nível de bifurcação que os compõem e que eles compõem ${ }^{13}$. (p. 33)

A iridescência da obra por fazer de Souriau e o binômio intensidade-multiplicidade em Deleuze consistem em modos de existência não fenomenológicos, mas potencialmente comunicáveis no nível não humano - como o das partículas subatômicas para a física, para continuar na analogia com a luz (parte matéria, parte onda). Nesse sentido, a especulação como forma de conhecimento imanente reúne epistemologia e estética nos modos de existência. Os afetos operam uma vinculação entre ambas, fazendo emergir realidades especulativas e múltiplas:

A organização de múltiplos níveis que possuem lógicas e organizações temporais diferentes, mas estão travados em ressonância um com o outro e recapitulam o mesmo evento em maneiras divergentes, remonta à ontologia fractal e à causalidade não linear subjacentes às teorias da complexidade. ... esses [níveis] poderiam ser vistos não como oposições ou contradições binárias [passado e futuro, mente e corpo, vontade e cognição], mas como níveis ressonantes. $\mathrm{O}$ afeto é seu ponto de 
emergência, em sua especificidade real [atual], e seu ponto de fuga, em singularidade, em sua coexistência e interconexão virtual ${ }^{14}$. (Massumi, 2002, p. 33)

A ressonância de níveis diferentes e até divergentes em Massumi (2002) é precisamente o que constitui a gambiarra como conceito para este estudo. Por ressonância, entende-se uma comunicação: uma mediação concretizante que não necessariamente resulta de uma cooperação. Trata-se da comunicação que se instaura pela disputa, pelo ruído e pelo paradoxo provocado pela ressonância entre lógicas dissonantes.

A ideia de gambiarra, ainda que tire proveito das noções de individuação e de instauração, ao se associar ao perspectivismo ameríndio representado principalmente pela predação antropofágica e a invenção de Virginia Kastrup (2007, 2008a, 2008b), busca, em última instância, uma dimensão autopoiética da mediação. Uma cognição canibal que mobiliza uma especulação inventiva. Assim, a invenção como processo da cognição faz com que a noção aqui pleiteada de gambiarra se situe no interstício entre as obras dos dois autores.

\section{COSMOLOGIA DA GAMBIARRA: AS MUITAS FORMAS DA PRECARIEDADE}

A cognição como invenção, para Virginia Kastrup (2007), reside na interseção entre seu campo de origem, a psicologia, as ciências cognitivas, e a filosofia. Dentre as vertentes corporificadas (embodied), a cognição atuada (enacted) que a autora retoma de Varela et al. (2001) estende o conceito para além da ideia de mente ou consciência - embora não as exclua. A cognição seria um processo que integra o corpo, sua fisiologia, o ambiente e as camada de sociabilidades e afetos:

A atuação [enaction] é um tipo de ação guiada por processos sensoriais locais, e não pela percepção de objetos ou formas. Os acoplamentos sensório-motores são inseparáveis da cognição vivida, aí incluídos acoplamentos biológicos, psicológicos e culturais.... A corporificação do conhecimento inclui, portanto, acoplamentos sociais, inclusive linguísticos, o que significa que o corpo não é apenas uma entidade biológica, mas é capaz de se inscrever e se marcar histórica e culturalmente ... invenção de mundo. (Kastrup, 2007, p. 153)

O conhecimento como um processo corporificado e atuado apresenta uma relação direta com as noções de mediação e individuação (Oliveira, 2003). Kastrup apropria-se de uma argumentação análoga à de Simondon, tratando do conceito de informação, que para ele é a força motriz da individuação. Kastrup (2008a)
${ }^{14}$ No original: "The organization of multiple levels that have different logics and temporal organizations, but are locked in resonance with each other and recapitulate the same event in divergent ways, recalls the fractal ontology and nonlinear causality underlying theories of complexity. These could be seen not as binary oppositions or contradictions, but as resonating levels. Affect is their point of emergence, in their actual specificity, and it is their vanishing point, in singularity, in their virtual coexistence and interconnection that critical point shadowing every image/ expression-event". 
afirma algo semelhante sobre a cognição inventiva: de acordo com a autora, "não se trata de perguntar como a cognição põe em relação um sujeito e um objeto, mas como, do exercício concreto da cognição, surgem sujeito e objeto" (p. 109).

Enquanto a inteligência é apenas a faculdade humana de emprego da lógica racional, a invenção é a linha que costura todos os elementos citados anteriormente (consciência, corpo, ambiente e dinâmicas sociotécnicas) dentro de um tempo indeterminado e criativo. Essa ideia é uma resposta às concepções de conhecimento como decodificação de problemas pré-fabricados. Kastrup (2007) reitera também que o conceito de invenção não se resume à habilidade humana da criatividade (que é uma espécie de conexão intuitiva de um sujeito ao fluxo do tempo criativo), já que a invenção desloca o humano do centro da dinâmica:

o automóvel, o telefone, o fax ou uma rede de computadores como a Internet não são soluções para o problema das longas distâncias que separam as pessoas, mas mudam nossa relação com o espaço e com o tempo que levaríamos para percorrê-las. Criam uma necessidade de comunicarmo-nos à distância, que surge para nós como um novo problema. (p. 212)

Esse contexto remete também a um horizonte político no sentido em que, como a própria autora também defende, essa noção de cognição está intimamente ligada à produção de subjetividade (Guattari, 2006). A discussão epistemológica presente nesse encontro entre filosofia, técnica e ciências cognitivas remete ao próprio conhecimento como atuação do e no mundo. A invenção não pode ser uma simples faculdade humana, pois faz parte da cocriação e codeterminação como apontam Varela et al. (2001) - da realidade, que surge da ressonância entre organismos biológicos, objetos e demais agentes/entidades (mentais, imaginárias, linguísticas). Esses acoplamentos ou agenciamentos ilustram um modo de ver a complexidade inerente dos sistemas que compõem a conjuntura social, que muitas vezes escapam aos limites da percepção humana. Para Kastrup (2007):

a cognição não funciona como se tivesse condições fechadas de possibilidade, mas acessa a complexidade de sua condição virtual, mantendo em tensão as antigas formas e aquilo que as problematiza. Trata-se de aprender a viver num mundo que não fornece um fundamento preestabelecido, num mundo que inventamos ao viver, lidando com a diferença que nos atinge. (p. 225)

Invenção, individuação e cognição atuada são maneiras de iniciar um diálogo conceitual com a complexidade, colocando-a no centro da questão do conhecimento, o que para Kastrup (2007) seria indicativo de um sistema cognitivo 
autopoiético. Esse movimento acompanha, como defende Luiz Alberto Oliveira (2003), algumas descobertas científicas no campo da biologia e da física no final do século XX, como o mapeamento do genoma, a teoria geral da relatividade e, complementarmente, a mecânica quântica. Elas reconfiguraram as concepções de realidade e trouxeram questionamentos sobre paradoxos, desafiando boa parte dos pressupostos científicos e filosóficos estabelecidos até então. Segundo Oliveira (2003),

a transformação de paradigmas correspondente à passagem da imagem mecânica para a complexa envolve uma deriva de fundamentos, um deslocamento ocorrido nas próprias bases da construção de nosso entendimento sobre os seres do mundo. Essa movimentação titânica pode ser apresentada como o destronamento do par conceitual substância-indivíduo em favor do par processo-informação. (p. 154, grifo do autor)

Tais teorias não trazem soluções prontas para problemas pré-fabricados, tais como a busca pela origem da vida ou pela partícula fundamental da matéria. Pelo contrário: contribuíram para a invenção de novos problemas baseados em termos totalmente novos. Em suma, construíram novos mundos, bem como novas formas de habitar, pensar e alterar esses mundos. Varela et al. (2001), por sua vez, reiteram o papel da constituição celular na percepção das cores pelos organismos vivos (bi, tri ou policromáticos) que acarretam formas diferentes de ver o mesmo mundo, isso para falar de apenas um sentido. A física e a biologia são repletas de exemplos de falhas perceptivas ou dissociações cognitivas que soam como imperfeições do aparato sensório-motor, mas que também podem ser interpretadas como traços deixados pelo processo da invenção que forja a conexão entre o organismo e o mundo que o rodeia: um reflexo do virtual no real. O próprio efeito óptico que permitiu o surgimento do cinema é um desses exemplos, graças ao qual imagens estáticas levemente diferentes entre si sendo alternadas acima de certa frequência nos dão a impressão de um movimento contínuo.

Para Yuk Hui (2016b), uma solução para compreender "a realidade da técnica", nesse contexto, seria rastrear diferentes relatos da gênese da tecnicidade, reforçando a primazia da perspectiva da localidade e da produção da alteridade radical como uma epistemologia, da qual a tecnicidade precisa ser parte integrante. Segundo o autor:

Pensamento científico e técnico emergem sob condições cosmológicas que são expressas nas relações entre humanos e seus meios [millieus], os quais nunca 
${ }^{15}$ No original: "Scientific and technical thinking emerges under cosmological conditions that are expressed in the relations between humans and their milieus, which are never static. For this reason I would like to call this conception of technics cosmotechnics".

${ }^{16}$ No original: "The strength of postcolonial theory, it seems to me, is that it effectively reformulates the question of power dynamics as narratives, and consequently argues for other, or different, narratives.

However, this might also be regarded as one of its weaknesses, since it tends to ignore the question of technology - a question which, I would argue, cannot be reduced to one of narratives".

${ }^{17} \mathrm{Em}$ março de 2015, a historiadora Kavita Philip (Universidade da CaliforniaIrvine) proferiu uma palestra na Universidade de WisconsinMilwaukee, na qual apresentou sua mais recente pesquisa sobre pirataria e o que os indianos chamam de economia Jugaad, um termo com uma assustadora semelhança com a gambiarra do português que fala justamente de flexibilidade e improviso em meio à precariedade. O conteúdo desta fala, fruto de uma pesquisa de pós-doutorado, ainda não foi publicado, mas será na forma do livro Ripped off: Pirate technologies, jugaad politics, and postcolonial modernities. são estáticos. Por essa razão, eu gostaria de chamar essa concepção da técnica de cosmotécnica ${ }^{15}$. (p. 18)

A gambiarra como mediação não consiste em uma forma de resistência exclusiva de um lugar precário - como se um ou mais sujeitos estivessem superando condições adversas para alcançar um patamar de produção técnica mais elevado. É, na realidade, uma cosmotécnica decolonial (Mignolo, 2011) que emerge a partir da precariedade. Nesse sentido, nem tudo é gambiarra: mas ela pode ser a chave para entender o encontro entre o real e seu virtual. Mesmo no processo de evolução das espécies, enxerga-se algo de bricolagem: “a junção de partes e itens em conjuntos complicados, não porque preencham qualquer projeto ideal, mas simplesmente porque são possíveis" (Varela et al., 2001, p. 255).

Entretanto, Hui (2016b) apresenta ressalvas quanto ao que ele entende como teoria pós-colonial:

A força da teoria pós-colonial, me parece, é que ela efetivamente reformula a questão das dinâmicas do poder como narrativas, e consequentemente defende outras, ou diferentes narrativas. No entanto, isso também pode ser considerado como uma de suas fraquezas, pois tende a ignorar a questão da tecnologia -que, eu diria, não pode ser reduzida a uma questão de narrativa ${ }^{16}$. (p. 56)

A opção por buscar uma cosmotécnica pós-colonial, contudo, está no entendimento de iniciativas similares, como a de Kavita Philip (2015) e a noção indiana de Jugaad ${ }^{17}$ e outros termos mapeados por Bruno (2017), como o shanzhai na China. Uma condição comum de precariedade - um devir precário - fundamenta essa cosmologia pós-colonial do Sul Global, indissociável de uma cosmotécnica.

Essa cosmotécnica é viabilizada empiricamente pela detecção de ações limitadas, ou melhor, restritas pela agência dos vários vetores do sistema. A necessidade desse direcionamento consiste numa forma de restrição, mas também numa irrupção improvisada - e por isso despudorada, nas palavras de Bruno (2017) -, que exprime o que entendemos por gambiarra: um processo emergente, uma superposição de fases (mediadas em diferentes ordens de magnitude) contingenciais, que se concretizam de maneira precária.

\section{LÓGICAS IRRACIONAIS E MOVIMENTOS ABERRANTES NOS HARDWARE, SOFTWARE E INTERFACES GRÁFICAS DOS VIDEO GAMES}

É certo que não há separação rígida que impeça a comunicação entre essas ordens de magnitude - pelo contrário, o entendimento dessa conexão é 
exatamente o que diferencia a epistemologia da complexidade daquelas calcadas no racionalismo determinista e nas leis imutáveis do positivismo. No entanto, é inegável que estas podem ser analisadas em escalas, um fato explicitado pela própria cultura digital. No que tange à gambiarra como modo de conhecer, enxergaremos as nuances do seu modo de existência em pelo menos três escalas: o hardware e suas manipulações; o software e sua prolongação na interface gráfica e, por último, a conexão sensorial entre essas interfaces e os usuários (ou jogadores, no caso dos video games).

O primeiro nível a ser contemplado é o do hardware. Quanto às características materiais, a maioria dos dispositivos que utilizamos é estruturada com níveis relativamente altos de clausura. Em suma, são projetados para dificultar e, se possível, inviabilizar a desconstrução das peças que os compõem, justamente para dificultar redirecionamentos de suas funções. Ainda assim, esses redirecionamentos acontecem, em grande parte devido ao que Douglas Hofstadter (1979) chama de "níveis de descrição"18 (p. 285).

Por mais que programadores e engenheiros de computação arquitetem seus trabalhos com uma intenção em mente, essa intenção existe enquanto um enunciado linguístico. Em contraste paradoxal com este enunciado, é erguida uma estrutura calcada em linguagem computacional. As duas linguagens, embora possam se comunicar, fundamentam-se em parâmetros e possuem aspectos divergentes. Daí surgem os desentendimentos comumente chamados de bugs e glitches, conhecidos pejorativamente como defeitos porque desagradam a parte humana da comunicação humano-máquina. No entanto, do ponto de vista do computador, o que está acontecendo é totalmente normal: defeitos, bugs e glitches não passam, portanto, de sintomas da atuação do ruído, uma grandeza necessária para a introdução da variabilidade, da diferença e, enfim, da comunicação (Krapp, 2011).

O potencial de desentendimentos aumenta na medida em que mais níveis de descrição estão envolvidos no processo. Quanto maior a distância coberta por este percurso, "menos e menos sabe-se com precisão o que mandamos o computador fazer! Camadas e mais camadas de tradução podem separar a margem dianteira de um programa complexo da sua contraparte operada em linguagem de máquina"19 (Hofstadter, 1979, p. 312). Em outras palavras, o que chamamos de defeito, bug ou glitch nada mais é do que resultado muitas vezes inevitável da instabilidade inerente aos computadores e do ruído criativo gerado pelas contradições entre seu modo de funcionar e o modo humano de pensar.

Essas contradições permitem, de maneira concreta, o redirecionamento dos vetores resultantes das interações entre níveis de descrição, mesmo no caso dos hardwares mais avançados. O console de video games PlayStation 3, por exemplo,
${ }^{18}$ No original: "levels of description".

${ }^{19}$ No original: "you know less and less precisely what you've told the computer to do! Layers and layers of translation may separate the 'front end' of a complex program from the actual machine language instructions". 
${ }^{20}$ Essa demanda flutua e, no momento, encontra-se em baixa devido, aos voláteis lastros das criptomoedas (De, 2019).

${ }^{21}$ Ainda assim, a indústria de eletrônicos vive sob a constante paranoia de uma era "pós-Lei de Moore" ("Nvidia plays", 2019). foi por vezes utilizado em grandes quantidades por organizações, que os ligavam em rede para que funcionassem em conjunto, como supercomputadores ("The PlayStation powered", 2010; Zyga, 2010). O que se passa em casos como estes é uma forma de gambiarra cara e em grande escala, mas, ainda assim, calcada no improviso e em uma espécie de precariedade: o PlayStation 3 não foi construído com esse propósito, mas o fato de ser resultado de redes complexas de produção e circulação o torna uma solução mais econômica, rápida e tão eficiente quanto um supercomputador construído da estaca zero para o projeto.

Descendo um degrau na escala, podemos ressaltar o fenômeno do uso de placas de vídeo, como as fabricadas pelas marcas Nvidia e AMD, cujo propósito original era atender a uma demanda de jogadores de video game. Tais placas são consumidas de modo avulso, podendo ser acopladas a sistemas montados pelos próprios consumidores, sobretudo os que desejam maior fidelidade e capacidade gráfica em monitores e TV de alta resolução (full HD ou até $4 \mathrm{k}$ ) e alta taxa de quadros por segundo.

Essas placas foram recentemente alvo de seu próprio redirecionamento de função, ao serem atacadas por mineradores de criptomoedas "caseiros". Sua complexa aglomeração de chips e processadores, que é projetada para viabilizar uma série de funções gráficas complexas, tem suas forças revertidas para o objetivo de operar cálculos brutos de maneira repetitiva e exaustiva - processo chamado de "mineração", por: a) configurar o modo de verificação do valor das criptomoedas; e b) recompensar os computadores que calculam as verificações com mais criptomoedas. Graças a esse desvio de função, a rede de produção de placas de vídeo encontrou problemas para suprir a demanda de mineradores, e os jogadores sofreram com altas nos preços e diminuição de oferta de placas ${ }^{20}$.

É importante notar que o poder de processamento bruto das placas é a força que os mineradores estão buscando. Esse poder de processamento cresce de maneira quase previsível e uniforme, sendo inclusive informalmente postulado pela Lei de Moore, que prevê que a quantidade de transistores adensados em um único microchip dobraria a cada dois anos, aumentando a velocidade de processamento em dispositivos como computadores e smartphones. Postulada em 1965, essa previsão se mantém relativamente consistente várias décadas depois ${ }^{21}$. A evolução de poder de processamento bruto, no entanto, é sempre acompanhada por inovações mais imprevisíveis e intermitentes situadas no modo como é aplicado em softwares e interfaces gráficas. E, enquanto a progressão uniforme da Lei de Moore é alavancada pela marcha ordenada e racional do conglomerado industrial de semicondutores, o campo do software e das interfaces gráficas imprime soluções de inovações cujas origens são muito mais humildes - mas igualmente poderosas. 
O grande exemplo que ilustra o modo de existência da gambiarra na engenharia de software e de interfaces gráficas é o mapeamento de bits e a invenção do mouse (cf. Johnson, 2001). Até então, a Lei de Moore avançava sem perturbações, condicionada apenas pelas novas demandas de tarefas a serem desempenhadas em computadores apenas com teclados: produção de textos, exibição de imagens, planilhas e cálculos. No entanto, em 1963 o primeiro mouse foi inventado por Douglas Engelbart. Sua concepção é calcada em duas gambiarras: do lado do hardware, Engelbart reconfigurou um objeto chamado planímetro, usado no campo da engenharia e do desenho técnico para medir superfícies planas.

Do lado do software, Engelbart usou uma gambiarra materializada em código, que vinculava o movimento dos sensores do mouse e passavam a alterar os pixels exibidos na tela. Depois disso, bastaria programar um cursor que obedecesse a um sistema de coordenadas, que por sua vez fosse modificado de acordo com a manipulação do mouse. Graças a isso, toda a linguagem da interação humano-computador se reconfigurou: janelas, menus, ícones e cursores reconfiguraram os destinos para os quais o poder de processamento deveria endereçar suas forças.

Vê-se nesse exemplo um tipo de pensamento que é claramente lógico, mas jamais poderia ser chamado de racional. É, de fato, uma lógica irracional, tal como David Lapoujade (2016) busca descrever a partir do pensamento de Gilles Deleuze:

Por isso, desde o começo até o final, as lógicas que interessam são aquelas que escapam de toda razão, a lógica do masoquismo, a lógica do sentido e do nonsense em Lewis Carroll, a lógica do processo esquizofrênico e, inclusive, a lógica de certos filósofos que, sob o manto da razão, inventaram lógicas muito pouco racionais (Hume, Bergson, Spinoza e Leibniz). A lógica tem sempre algo de esquizofrênico em Deleuze ${ }^{22}$. (p. 15)

Dessas lógicas irracionais, emergem o que Lapoujade (2016) chama de movimentos aberrantes. Eles podem se manifestar de maneira espontânea como as imagens que nos aparecem em sonhos ou mesmo os pensamentos que nos acometem sem motivo aparente durante o cotidiano, mas podem também ser inventados, no sentido cognitivo do termo.

As formas de expressar imagens e movimentos do cinema constituem movimentos aberrantes (Lapoujade, 2016, p. 29). Inventam lógicas espaciais impossíveis, como os corredores paradoxais filmados por Stanley Kubrick, em O iluminado; ou tempos irracionais, como a amálgama de passado, presente e futuro de Alan Resnais, em $O$ ano passado em Marienbad. Na cultura digital, a
${ }^{22}$ No original: "Por eso, desde el comienzo hasta el final, las lógicas que interesan son aquellas que escapan a toda razón, lógica del masoquismo, lógica del sentido y del sinsentido en Lewis Carroll, lógica del proceso esquizofrénico o incluso lógica de ciertos filósofos que, bajo manto de razón, inventaron lógicas en verdad muy poco racionales (Hume, Bergson, Spinoza o incluso Leibniz). La lógica tiene siempre algo de esquizofrénico en Deleuze". 
manipulação do processamento gráfico gera, por meio de um movimento aberrante, a lógica irracional da interface gráfica. Por sua vez, esse processamento é intensificado por estratégias múltiplas de caracterização do espaço e do tempo nos video games, fortemente carregadas pelo binômio precariedade-improviso.

A invenção do espaço tridimensional nos video games, por exemplo, ocorreu em vários momentos. A grande maioria deles vinda de lugares improváveis, como o quarto dividido por dois universitários ingleses, David Braben e Ian Bell. Coube a eles a missão de entrar na corrida pela criação do primeiro jogo em três dimensões. Muitas formas de fabricar a sensação de percorrer um espaço tridimensional foram tentadas. A primeira delas em 1973, com Maze War, que rodava em um mainframe sitiado no centro de pesquisa da NASA, na Califórnia. Em 1982, 3D Monster Maze seria o primeiro exemplar de espaço tridimensional em um jogo de computador caseiro. O resultado, no entanto, era um espaço pequeno e labiríntico, com uma perspectiva imóvel. O jogador podia caminhar apenas em turnos, como uma peça de xadrez saltando de casa em casa, sem a capacidade de olhar para os lados ou para baixo/cima.

Menos de dois anos depois, em 1984, Braben e Bell lançariam sua criação conjunta: Elite. $\mathrm{O}$ jogo demonstrou-se tão à frente da concorrência que poderia ser acusado de usar mágica no lugar de programação. O jogador pilota uma nave em pleno espaço, direcionando-a em qualquer ângulo e na velocidade que desejasse. Seu espaço é não só tridimensional, mas contínuo e expansivo, explorável em todas as direções. Para coroar o feito, Elite não consistia em um simples labirinto, mas em um universo aberto com oito galáxias, cada qual com 256 sistemas solares - estes, por suas vezes, com diferentes alienígenas, naves espaciais, sistemas econômicos: um circuito de processos extremamente amplo, parido por algoritmos. Tudo isso foi desenvolvido pelos dois estudantes para um computador caseiro - o BBC Micro - que gozava de $22 \mathrm{~kb}$ de memória.

A precariedade exigiu o improviso: o jogo foi programado literalmente economizando cada bit da memória. Foi necessário recorrer a usos de matemática até então inutilizada nos video games, como a sequência de Fibonacci -

${ }^{23}$ Já há alguns anos entendese que a famosa sequência popularizada pelo matemático italiano teria tido origem na Índia pelo menos 500 anos antes (Singh, 1985). descoberta há vários séculos ${ }^{23}$. O resultado técnico ultrapassou o que qualquer megaempresa ou centro de pesquisa conseguira atingir até então. As futuras inovações no processamento gráfico continuariam a demonstrar que abundância de recursos era menos importante do que o ímpeto das lógicas irracionais. Foi assim com a empresa id Software, formada por dois programadores iniciantes: John Carmack e John Romero. A dupla - principalmente Carmack - seria responsável por possibilitar o mapeamento de texturas nos mundos tridimensionais dos video games tal como nunca havia sido visto. O primeiro jogo a demonstrar a tecnologia de ray casting foi Wolfenstein $3 D$ (1992), também responsável por 
inaugurar efetivamente o gênero de jogos de tiro em primeira pessoa. A genialidade de Carmack não se devia ao fato de conseguir projetar texturas em objetos tridimensionais, mas sim fazer com que essas texturas fossem processadas de forma quase instantânea: uma velocidade até então tida como impossível. Isso permitiu não apenas um desempenho melhor do jogo, mas um ritmo acelerado de movimento por parte do jogador, que caracterizaria ainda mais o sucessor de Wolfenstein 3D: o influente Doom (1993).

A velocidade com que as cores e formas apareciam e se modificavam conectava-se com os olhos dos jogadores criando uma lógica temporal e rítmica inédita - e irracional, no sentido defendido por Lapoujade (2016), inoculando-os com novas sensorialidades, habilidades e formas de jogar. De fato, o que Carmack e Romero fizeram com Wolfenstein $3 D$ e Doom se aproxima do que Engelbart fez com o mouse: a partir de inversões e reversões do poder de processamento, foi cunhado um novo tipo de plataforma sensorial para a fruição do usuário. É o que Kristine Jørgensen (2013) define como "mundo de jogo": quando a capacidade sensorial humana se encontra com o resultado sensível do trabalho interno do computador.

\section{CONSIDERAÇÕES FINAIS: GAMBIARRA COMO MULTIPLICIDADE}

Os níveis de descrição envolvidos nesse fenômeno - a manipulação do processamento em hardware, dos algoritmos do software, da criação de novas formas visíveis e manipuláveis da interface gráfica - consistem em um conjunto de vetores que Manuel Delanda (2002/2005), mesclando matemática e filosofia deleuziana, chamará de graus de liberdade, ou seja, as formas pelas quais um sistema pode se reorganizar. Cada um desses níveis mobiliza outros tantos subníveis, compostos por outros graus de liberdade. A atuação conjunta desses vetores não é o resultado frio de um cálculo matemático, mas sim condicionado pela força divergente e sempre mutante do que Delanda (2002/2005), a partir de Deleuze, entende como multiplicidade:

Multiplicidades são, por designação, obscuras e distintas: as singularidades que definem uma multiplicidade agrupam-se em conjuntos, e estes conjuntos não são todos estabelecidos ao mesmo tempo, e sim se estruturam de tal forma que especificam a natureza de uma multiplicidade progressivamente, enquanto se desdobram seguindo sequências recorrentes ${ }^{24}$. (p. 16)

De forma ainda mais complexa, é possível mobilizar esses graus para criar lógicas irracionais. Mas esse processo não surge, para usar a alegoria de Kastrup
${ }^{24}$ No original: "Multiplicities are, by design, obscure and distinct: the singularities which define a multiplicity come in sets, and these sets are not given all at once but are structured in such a way that they progressively specify the nature of a multiplicity as they unfold following recurrent sequences". 
(2007, p. 27), como quem monta um quebra-cabeça, com a imagem já dada. Emerge, em vez disso, de vetores cuja potência é obscura e contingente. De fato, o pareamento precariedade-improviso, bem como seus vieses político, estético e pós-colonial, aponta para um conjunto de singularidades - conceito que Delanda (2002/2005) entende como as grandezas que desenham tendências para o desdobramento de um fenômeno. No caso da gambiarra, essas singularidades fariam desdobrar um modo de pensamento técnico.

Fugindo do essencialismo, a gambiarra como multiplicidade aponta para uma forma de conhecer livre das amarras das leis imutáveis e dos percursos pré-concebidos das lógicas racionais. Por isso, não pode ser constrangida a posicionamentos geográficos e socioeconômicos - o que não nos impede de compreender o modo como a perspectiva pós-colonial condiciona seu aparecimento em contextos diversos a ela. Acreditamos, por fim, que há exemplos suficientes na história da cultura digital para justificar um olhar que entenda a invenção do conhecimento como um processo paradoxal e dissonante. $\mathbf{M}$

\section{REFERÊNCIAS}

Bruno, F. (2017). Objetos técnicos sem pudor: Gambiarra e tecnicidade. Revista Eco-Pós, 20(1), 136-149. doi: 10.29146/eco-pos.v20i1.10407

Clark, A. (2001). Mindware: An introduction to the philosophy of cognitive science. Nova York, NY: Oxford University Press.

De, N. (2019, 29 de janeiro). AMD cites 'absence' of GPU sales to crypto miners in Q1 estimate. Coindesk. Recuperado de https://bit.ly/34iZUdr

Delanda, M. (2005). Intensive science and virtual philosophy. Londres, Inglaterra: Continuum. (Obra original publicada em 2002)

Galloway, A. (2012). The interface effect. Cambridge, Inglaterra: Polity Press.

Grusin, R. (2015). Radical mediation. Critical Inquiry, 42(1), 124-148. doi: $10.1086 / 682998$

Guattari, F. (2006). Caosmose: Um novo paradigma estético. São Paulo, SP: Editora 34.

Hardt, M., \& Negri, A. (2001). Império. Rio de Janeiro, RJ: Record.

Hardt, M., \& Negri, A. (2005). Multidão: Guerra e democracia na era do Império. Rio de Janeiro, RJ: Record.

Hardt, M., \& Negri, A. (2016). Bem-estar comum. Rio de Janeiro, RJ: Record.

Hennion, A. (2010). Loving music: From a sociology of mediation to a pragmatics of taste. Comunicar, 17(34), 25-33. doi: 10.3916/C34-2010-02-02

Hofstadter, D. (1979). Gödel, Escher, Bach: An eternal golden braid. Nova York, NY: Basic Books, Inc. 
Hui, Y. (2016a). On the existence of digital objects. Minneapolis, MN: University of Minnesota Press.

Hui, Y. (2016b). The question concerning technology in China: An essay in Cosmotechnics. Falmouth, Inglaterra: Urbanomic Media.

Johnson, S. (2001). Cultura da interface: Como o computador transforma nossa maneira de criar e comunicar. Rio de Janeiro, RJ: Zahar.

Jørgensen, K. (2013). Gameworld interfaces. Cambridge, MA: MIT Press.

Kastrup, V. (2007). A invenção de si e do mundo: Uma introdução do tempo e do coletivo no estudo da cognição. Belo Horizonte, MG: Autêntica.

Kastrup, V. (2008a). A cognição contemporânea e a aprendizagem inventiva. In V. Kastrup, S. Tedesco, \& E. Passos, Políticas da cognição (pp. 93-112). Porto Alegre, RS: Sulina.

Kastrup, V. (2008b). Autopoiese e subjetividade: Sobre o uso da noção de autopoiese por G. Deleuze e F. Guattari. In V. Kastrup, S. Tedesco, \& E. Passos, Políticas da cognição (pp. 46-63). Porto Alegre, RS: Sulina.

Krapp, P. (2011) Noise channels: Glitch and error in digital culture. Minneapolis, $\mathrm{MN}$ : University of Minnesota Press.

Lakoff, G., \& Johnson, M. (1999). Philosophy in the flesh: The embodied mind and its challenge to Western thought. Nova York, NY: Basic Books.

Lapoujade, D. (2016). Deleuze: Los movimientos aberrantes. Buenos Aires, Argentina: Cactus.

Massumi, B. (2002). Parables for the virtual: Movement, affect, sensation. Durham, NC: Duke University Press.

Mbembe, A. (2017). Critique of black reason. Durham, NC: Duke University Press.

Mignolo, W. (2011). The darker side of Western Modernity: Global futures, decolonial options. Durham, NC: Duke University Press.

Norman, D. (1993). Things that make us smart. Cambridge, MA: Perseus Books. Nvidia plays the diversification game. (2019, 23 de fevereiro). The Economist. Recuperado de https://econ.st/2wl7KXJ

Oliveira, L. A. (2003). Biontes, bioides e borgues. In A. Novaes (Org.), O homem máquina: A ciência manipula o corpo (pp. 139-173). São Paulo, SP: Companhia das Letras.

Pelbart, P. P. (2017). O avesso do niilismo: Cartografias do esgotamento. São Paulo, SP: $n-1$ edições.

Philip, K. (2015, 12 de março). Pirate copying, Jugaad economics: Postcolonial tech and developmental leapfrogging [arquivo de vídeo]. Recuperado de https://bit.ly/2RjAvLx 
Rosas, R. (2007). Gambiarra: Alguns pontos para se pensar uma tecnologia recombinante. Caderno Videobrasil, 2(2), 36-52. doi: 10.22409/gambiarra. v1i1.29620

Simondon, G. (2009). The position of the problem of ontogenesis (G. Flanders, Trad.). Parrhesia Journal, (7), 4-16.

Simondon, G. (2017). On the mode of existence of technical objects. Minneapolis, MN: Univocal.

Singh, P. (1985). The so-called Fibonacci numbers in ancient and medieval India. Historia Mathematica, 12(3), 229-244. doi: 10.1016/0315-0860(85)90021-7

Sodré, M. (2014). A ciência do comum. Petrópolis, RJ: Vozes.

Souriau, É. (2015). The different modes of existence. Minneapolis, MN: Univocal.

Stengers, I., \& Latour, B. (2015). The sphinx of the work. In É. Souriau. The different modes of existence (pp. 11-94). Minneapolis, MN: Univocal.

The PlayStation powered super-computer. (2010, 4 de setembro). BBC. Recuperado de https://bbc.in/2JMLb0Y

Varela, F., Thompson, E. T., \& Rosch, E. (2001). A mente corpórea: Ciência cognitiva e experiência humana. Lisboa, Portugal: Instituto Piaget.

Viveiros de Castro, E. (2013). A inconstância da alma selvagem e outros ensaios de antropologia (5a ed.). São Paulo, SP: Cosac Naify.

Zyga, L. (2010, 2 de dezembro). US Air Force connects 1,760 PlayStation 3's to build supercomputer. Phys.org. Recuperado de https://bit.ly/34eghYY

Artigo recebido em 29 de abril de 2019 e aprovado em 24 de março de 2020. 